The LANCKT,] DR. RINGER AND DR. PHEAR : THE DIAGNOSIS OF CARDIAC MURMURS. [FeB. $10,1894.325$

\section{SOME PRACTICAL POINTS CONCERNING THE DIAGNOSIS OF CARDIAC MURMURS.}

BY SYDNEY RINGER, M.D. LOND., F.R.S.,

PIISICIAN AND PROFESSOR OF CLINICAL MEDICINE AT UNIVERSITY COLLEGE HOSPITAL;

$$
\text { AND }
$$

ARTHUR G. PHEAR, M.B. CANTAB, M.R.C.P. LOND.

THERE are many considerations of practical interest in connexion with the examination of the heart which deserve attention if fallacies are to be avoided and reliable diagnoses obtained. We desire here to notice two such matters-(1) the effect of exercising pressure with the stethoscope, and (2) the influence of slight change in posture. We have not been able to find any reference to either of these points in the various text-books on the subject.

\section{The Modification of Murmurs by Pressure.}

If, when listening to a murmur, pressure be made with the stethoscope the character of the murmur is altered. This modification is twofold - the murmur is weakened and its pitch is raised. With a few exceptions, to which reference will be made presently, we have found this effect of pressure to be universal. It may be brought about, however, as might be expected, more readily in some cases than in others thus in children with elastic and resilient chest walls slight pressure is sufficient to cause a well-marked modification; to produce the same degree of change in adults with more rigid chest walls a greater amount of pressure must be employed; while the effect is least marked in old people whose rib cartilages have become ossified and whose chest walls are extremely rigid and unyielding. The modification is more readily obtained in fat than in thin people. The slightest pressure is often sufficient to considerably modify the murmur ; even the weight of the stethoscope may cause a difference, so that in the pursuance of these investigations we have found it necessary to use a binaural in place of the wooden stethoscope, with which great pressure may be exercised nnwittingly; with the binaural stethoscope the pressure employed is under control and can be graduated. It is not necessary that the pressure should be applied over the point of greatest intensity of the murmur or over the point of production. Wherever the murmur can be heard the effect of pressure is the same ; indeed, it can often be more readily produced at a distance from the point of production than near to it. A case may be quoted of mitral regurgitation in a boy five years of age in whom a long, loud, systolic murmur was audible all over the chest, back, and front, the spot of maximum intensity being at the apex-beat. 'The murmur was heard very distinctly at the angle of the left scapula, but on exerting the slightest pressure at this point it became exceedingly faint; a moderate amount of pressure sufficed to obliterate it. In front the effect of pressure was evident more in modification of pitch than of intensity, gentle pressure causing a wellmarked rise of pitch. On increasing the pressure the murmur became rapidly weaker at the same time as the pitch was raised.

The same points may be illustrated by experiment. If water at high pressure be allowed to pass through indiarubber tubing, in the course of which a small constriction has been made by string or otherwise, a loud, continuous murmur is generated. If the tubing be laid on a piece of board the murmur is conducted along the board and may be heard on applying a stethoscope to the board at a distance from the tubing; if a thin piece of cotton wool be now placed between the stethoscope and the board, and the former be gradually pressed down firmly on to the latter, the murmur becomes weak and its pitch is raised-the same result as is obtained when auscultating a cardiac murmur. It will be noticed that in this experiment the production of the murmur is in no way interfered with, and the conclusion is inevitable that the modification is one of conduction, not of production; this throws some light on the point referred to above-namely, that in auscultation of the chest, no matter where the stethoscope be applied, provided only a murmur be audible, the effect of pressure is the same.

It is laid down in text-books, and generally accepted, that the intensity of a pulmonary hæmic murmur is increased by pressure. This is undoubtedly true in some instances, and in many children a murmur can be actually produced where none was audible before by properly applied pressure; we find, however, that in by far the larger number of hæmic murmurs pressure, as would be expected, has the same effect as in other murmurs-namely, the intensity of the murmur is not increased, but diminished, and the pitch of the murmur is raised. Soft hæmic murmurs are readily obliterated before any modification of pitch can be detected; with louder murmurs the earliest effect of pressure is usually to raise the pitch before any notable weakening occurs, a greater degree of pressure being required to weaken the murmur than to modify the pitch. We are inclined to think that this variation in the behaviour of hæmic murmurs to pressure depends on whether the actual production of the murmur is modified by the pressure or not; in those cases where the pulmonary artery can be actually pressed upon and dimpled doubtless an existing murmur will become more loud or a murmur will be produced where there was none before. In order to produce a murmur in a child it is necessary to use a stethoscope with a small chest-piece which can be fitted between the rib cartilages in the second left interspace, and firm pressure inwards and backwards must be exercised; it is clear that a murmur thus produced is the result of an actual flattening of the pulmonary artery by the pressure employed. In the majority of cases of hæmic murmur, however, where pressure weakens the murmur the production of the murmur cannot anyhow be supposed to be modified, since the change in character may be obtained equally well, or even more readily, at a distance from the point of production than immediately over this point; the modification, therefore, has to do solely with conduction.

Some comment is necessary on the subject of "pitch" in connexion with murmurs. The word is apt to be misleading, inasmuch as, strictly speaking, murmurs cannot be said to possess definite pitch except in rare cases of truly musical murmurs. A murmur should properly be regarded as an aggregation of noises affording a general impression of pitch so far that one murmur can be said to be of higher or lower pitch than another; but the pitch cannot be defined. On exercising pressure while listening to a murmur the impression afforded is that the lower-pitched noises which enter into the composition of the murmur are weakened or abolished, leaving the higher-pitched noises prominent. This produces the broad effect of rise in pitch. The high-pitched elements of a murmur bear no such relation to the low-pitched elements as harmonics to the ground note of a musical sound; a murmur, being a combination of noises, possesses no harmonics. In the uncommon cases of true musical murmur, to which definite pitch can be assigned, the pitch remains constant whatever the pressure be. Similarly if a vibrating tuning-fork be placed at one end of a board, and the other end be auscultated (a thin piece of cotton wool having been placed between the chest-piece of the stethoscope and the board), the note heard remains constant, its pitch being unaltered whether firm or light pressure be exercised with the stethoscope.

In differentiating between the various murmurs which may be produced at the cardiac orifices reliance is usually placed on these points: (1) the time of the murmur; (2) the position of maximum intensity; (3) the degree and direction of conduction and conrection (convection in the case of murmurs nearly always playing the more important part) ; and (4) other qualities, which may be included generally under pitch and timbre. The consideration of pitch, harshness, blowing character, and such qualities is held to be of less importance than the determination of the point of maximum intensity and the degree and direction of convection or conduction, and it is doubtless right to give to these latter the first place ; still, supposing a murmur to be heard at the base of the heart and a murmur also at the apex, and supposing the one to be a low-pitched, rough murmur and the other a high-pitched, blowing one, it would be most tempting to conclude that with characters so opposite the two murmurs must be distinct; and yet it will be found that the first murmur can be brought to assume all the characters of the second by the application of pressure -it will become soft, high-pitched, and blowing. We have found it frequently to be the case that without any variation in the degree of pressure employed the pitch of a murmur is different at different points of the chest; the alteration is usually in the direction of a rise in pitch as the stethoscope is carried away from the point of production of the murmur- 
the further from the point of production the higher the pitch. So the conclusion cannot justly be made that two murmurs are distinct because they contrast with one another in point of pitch and timbre. Of much greater value is the consideration of the intensity of the murmur at different points if the murmur is heard clearly at the apex and also clearly at the base, and if there is an intermediate point between apex and base at which it is not heard at all, or at any rate less loudly than at either apex or base, then it may be safely concluded that one has to deal with two separate murmurs and not with a single murmur conducted from one point to another. Here also there is a source of fallacy ; if, while listening to the intermediate point between base and apex, pressure be applied, the murmur will be weakened, and very slight pressure will suffice to bring about this result, as we have shown above; so little, that the observer may not be cognisant of having altered the pressure, especially if he be using a wooden stethoscope. Thus a single murmur, generated, say, at the pulmonary orifice and conducted from base to apex, may readily assume the character of and be mistaken for a double murmur, the one basic, the other apical. To obriate such fallacies we would suggest that the use of the wooden stethoscope be supplemented-not replaced-by the binaural, a simple precaution by which the misapplication of pressure can be easily avoided.

It remains to be noticed that these effects of pressure are not observed solely in connexion with murmurs ; the second sound of the heart becomes higher-pitched and weaker when pressure is employed. In many cases we have been able to weaken italmost to obliteration; in a few it has becomeactually obliterated. The breath sounds also are considerably modified; not only do they become raised in pitch and weakened, but their vesicular character is lost. To obtain this result considerable pressure must be employed; less pressure is necessary in children than in adults.

\section{The Effect on Murmurs of Slight Change in} Posture.

We have been much impressed with the importance of posture in comparing the loudness of a cardiac murmur at different points. A very slight inclination to one side or the other may cause the point of maximum intensity of a murmur to shift, this occurring more readily on leaning towards the left than towards the right side, and being much more noticeable in basic than in apical murmurs. We have observed this effect of posture in the murmurs of aortic regurgitation, of aortic stenosis, and in pulmonary hæmic murmurs. As an example, a case may be given of a man with aortic disease in whom a well-marked double basic murmur was heard on auscultation of the heart. When the man was lying on his back the diastolic murmur was heard loudest close to the sternum in the second left interspace, the systolic murmur being most plainly audible in the second right interspace close to the sternum. After turning over towards the left through an angle of 45 degrees only the points of maximum intensity of both the murmurs were found to have shifted three-quarters of an inch to the left the diastolic murmur being heard best still in the second left interspace, but well away from the sternum, while the systolic murmur was loudest to the left of the sternum in the second interspace; the apex beat had shifted nearly an inch to the left of its former position. After turning from the back towards the right through the same angle it was found that the point of maximum intensity of the diastolic murmur had come to lie on the right of the sternum; the intensity of the systolic murmur to the right of the sternum was notably increased, but its position had hardly altered; the apex-beat had shifted to the right. It may be remarked in passing that we find the point of maximum intensity of the murmur of aortic regurgitation to lie much more commonly to the left than to the right of the sternum; this is at variance with the statements made in most text-books, in which the murmur is described as being usually most plainly heard to the right of the sternum. Another case may be quoted of hæmic murmur in a woman suffering from chlorosis. With the patient lying on her back the murmur was heard loudest in the second left interspace about one inch from the sternal edge; the result of turning towards the left was that the point of maximum intensity shifted half an inch further out to the left. On turning towards the right the murmur became, on the whole, weaker than before, but the loudest point was close up to the left sternal edge in the second interspace, and it became audible also in the second right interspace at a spot where it was not to be beard when the patient was lying on her back. Other similar instances could be given, but the above cases are sufficent to illustrate the modification produced by leaning to the one side or the other and to indicate the importance of posture in making observations as to the relative loudness of a murmar on the two sides. That these phenomena are due to an actual change in the position of the heart is indicated by the apex-beat, which may be observed to move half an inch or more out of its previons position, much more readily to the left than to the right. In many cases, after the patient has turned towards the left we have noticed some delay in the shifting of the beart, the point of maximum intensity of the murmur remaining for one or two minutes in the same position as when the patient was lying on his back. There has been in some cases a similar delay in the return of the heart after the patient has turned from the left so as to lie again on his back; the heart has always, however, in the end reverted to its original posi. tion without any further change of posture. The intensity of the second sound is modified by posture in a similar manner The result of leaning to the left may be that the second sound, previously louder on the right side than on the left, becomes louder on the left than on the right; or the point of maximum intensity on the left side from the beginning may shift half an inch or more furtber to the left; or second sound which was previously weak on both sides mar become loud on the left and almost inaudible on the right The slightest inclination to the left may be sufficient to greatly intensify the second sound as heard on this side.

THE SIGNIFICANCE OF THE "FUNNEL SHAPED " AND "BUTTON-HOLE" OPEN-

\section{INGS IN STENOSIS OF THE} CARDIAC VALVES.

BY HARRY CAMPBELL, M.D. LOND., PIIYSICIAN TO THE NORTH-WEST LONDON HOSPITAL.

WHEN the mitral and aortic openings or their counterparts in the right heart are constricted by disease they tend to conform to one of two types- $v i z$, (1) the funnel, and (2) the slit (known in the case of the auriculo-ventricular orifices as the "button-hole" opening). 1. The funnel-shaped opening at the mitral orifice (for convenience I shall confine my remarks to the left heart) is often formed by the simple union of the two mitral cusps at their contiguous edges, the apex of the cone thus formed projecting into the ventricle. In like manner the aortic valves may becom blended so as to form a funnel pointing towards the aorta. The walls of the mitral funnel are sometimes 80 smooth and regular as to suggest congenital malformation, though such cases are now pretty generally recognised to be always the result of endocarditis. The funnel, or cone, is not always a perfect geometric figure-i.e, one consisting of a series of gradually diminishing circles : the smaller orificethe orifice of egress-may vary between a perfect circle and a long, narrow slit, in which latter case the funnel will tend to be flattened. Nevertheless. there is always an approach to a perfect geometric cone. 2. The "button-hole " orifice takes the shape of a slit or chink. This, as has been just seen, may be approached by a gradually narrowing passage, forming a flattened funnel, or it may occur as a chink in the centre of a more or less flat diaphragm stretching across the stenosed orifice. An explanation of this tendency to one of two definite types bas now to be found. I shall seek to show that it depends very largely upon certain hydraulic laws and that the "funnel-shaped" and "button-hole" orifices permit the largest available amount of fluid to pass through them. The flow of fluids through orifices has been carefully studied by physicists, notably by engineers, and it has been found that when fluid is discharged through an orifice the sectional area of the jet is always less than the area of the orifice. The degree to which the cross section of the jet is diminished is technically called the vena constricta, and the relation which its area bears to that of the orifice, the coefficient of discharge. When a fluid is allowed to escape from a vessel through a circular orifice in its side with sharp edges-i.e., through a mere partition-the diameter of the jet is about 80 per cent. less than that of the orifice, and the relation of the cross rection of the jet to the orifice-i.e., the coefficient of 